\title{
Properties of Broezel static probe
}

\author{
Peter Gašparovič ${ }^{1, a}$, Karol Semrád ${ }^{1}$ and Miroslava Cúttová ${ }^{1}$ \\ ${ }^{1}$ Technical University of Kosice, Faculty of Aeronautics, Rampova 7, 041 21, Kosice, Slovakia
}

\begin{abstract}
The properties of flat static probe designed by Broezel and used in sailplanes are investigated for its planned use in low speed tunnel. Both the numerical CFD model and experiment in low speed wind tunnel confirm yaw insensitivity of the static pressure measured by the probe. The results indicate that the probe is sufficiently accurate for its planned use in wind tunnel measurements.
\end{abstract}

\section{Introduction}

The most common device for measurement of static pressure is a static tube. However, the static tube is not suitable when airflow direction is not known in advance. Examples of "standard" and Prandtl's pitot-static tubes are on the figure 1 . The static tube is obtained from pitotstatic tube by omitting total pressure port.

a)
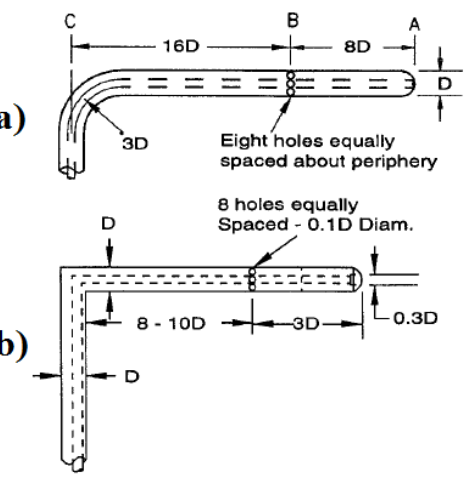

Figure 1. Pitot-static tubes a) N.P.L "Standard", b) Prandtl's design, [1]

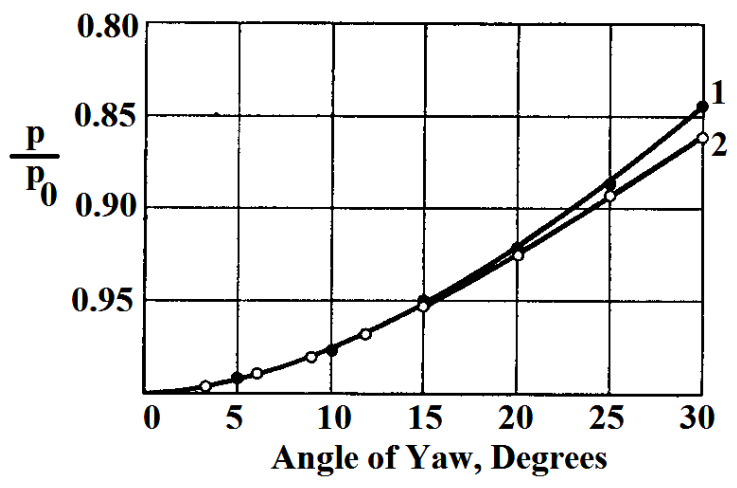

Figure 2. Influence of yaw on reading of static tube, [7]
Even when the dominant direction is known, strong directional sensitivity of the static tube makes accurate measurement very difficult an unreliable. On the figure 2 is shown influence of the angle of yaw on the static error measured by pitot-static tubes (1- N.P.L. Standard, 2Round Nosed). Indeed, the directional dependency of the static pressure of a static tube has very narrow range of yaw angles, where the error is below $1 \%$ (typically less than plus/minus $5^{\circ}$ ). On the contrary, the total pressure of a decent pitot tube has usable range of plus/minus $10^{\circ}$ and the error in most of this range is much lower and more gradual.

Some different types of the static probes, which are promised to be directionally insensitive, are on the following figures.

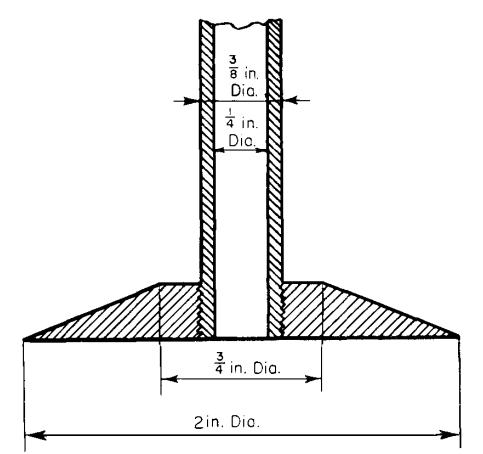

Figure 3. Disc static probe, [6]

On the figure 3 is a disc static probe with only one static port, which is directionally very sensitive. However, the double disc static probe on the figure 4 is directionally insensitive in all planes but its relatively bulky. There are other probes, which are directionally insensitive too, but are more practical for aeronautical applications. Very interesting probe was designed by A.M.O. Smith (figure 5). However, this probe has complicated geometry, which is not trivial to manufacture

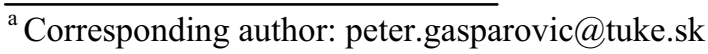


(it must be smooth and accurate at the same time). The directional sensitivity of static probe by A.M.O. Smith, calculated by inviscid panel method, is on the figure 6 .

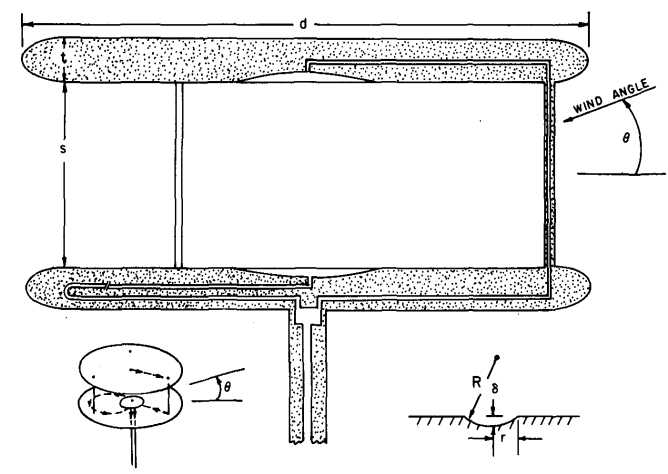

Figure 4. Double disc omnidirectional static probe, [5]

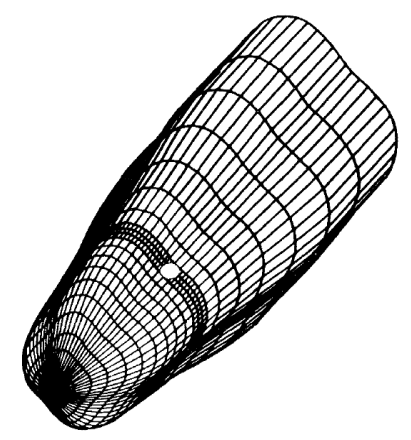

Figure 5. Static probe of A.M.O. Smith, [8]

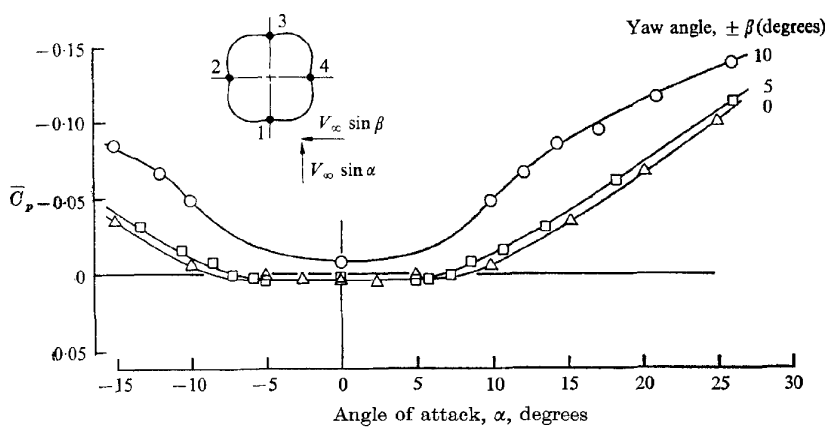

Figure 6. Characteristics of A.M.O. Smith static probe, [8]

The directional sensitivity of Smith probe is perfectly acceptable, but there are other solutions which are more easily manufacturable, for example wedge probe described in [4] and [3] or reversed delta wedge described in Patent [2]. These devices are expected for use at speeds approaching or exceeding sound of speed. However, for low speeds there is even simpler solution Broezel flat static probe.

\section{Broezel flat static probe and its CFD analysis}

Sailplanes are flying without engines and to keep them at the safe altitude the pilot must use natural ascending motion of the air. To effectively use this motion, there is a need to differentiate the climbing motion of the air from the climbing motion of the sailplane at the expense of kinetic energy of the sailplane. One needs two inputs total pressure at the speed of sailplane and static pressure. Whereas measuring total pressure is relatively simple task, to accurately measure the static pressure is almost unrealizable, because the sailplane is in the state of permanent change of its position relatively to surrounding airflow. That perpetual unrest creates dynamic changes of surface pressures over whole surface of the glider.

Sometime around year 1985, German inventor Rudolf Broezel, came with his own solution. He devised reliable static probe, which consisted of simple flat and narrow plate with static ports. Later he sold his design to the company ESA systems, which is still manufacturing it and offering under the name STATEK (STAtic probe + Total Energy Compensation), see figure 7.

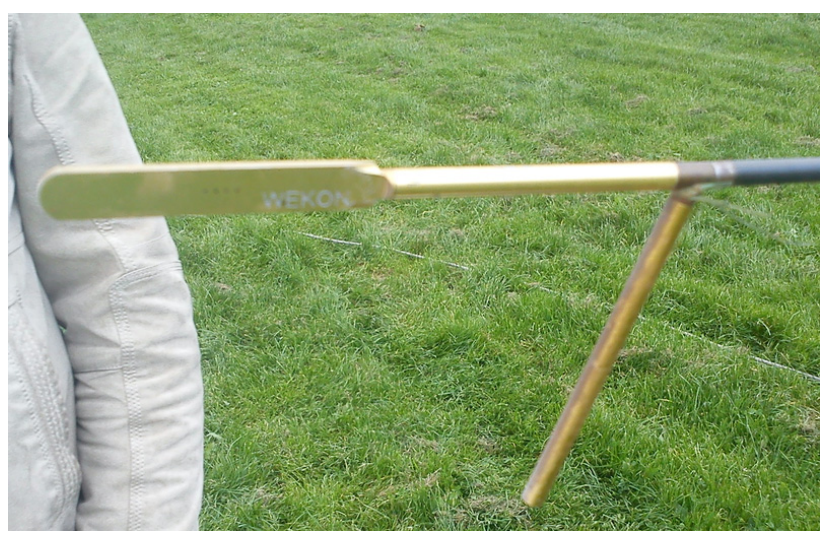

Figure 7. Static probe STATEK by R. Broezel

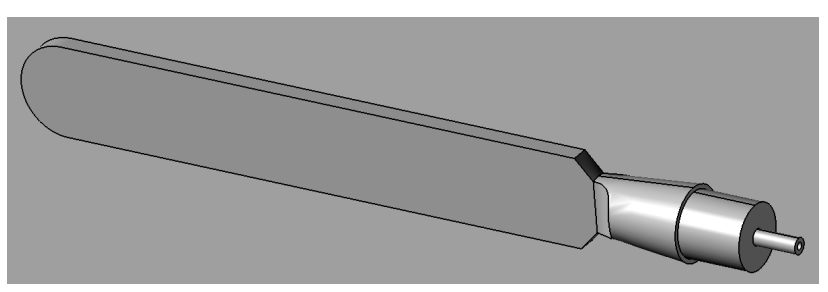

Figure 8. CAD geometry of Broezel static probe

In order to investigate its suitability for measurement of static pressure in our low speed wind tunnel, the geometry of the probe was reversely engineered from the photograph. Its CAD geometry is shown on the figure 8 .

The computational mesh was created in program IcemCFD. The mesh is unstructured, contains 1.6 million cells and prism elements in boundary layer were scaled to achieve $\mathrm{y}+<1$. The numerical solution of CFD analysis was performed in software Ansys CFX. The flow was modeled by the Reynolds Averaged Navier Stokes equations and SST turbulence model, with the ability to 
model the laminar-turbulent transition in boundary layer. The CFD analysis results are on the following pictures. The pressure coefficient at zero yaw of the Broezel static probe is on the figure 9. It can be seen, that the centre part of the plate has relatively mild pressure gradient.

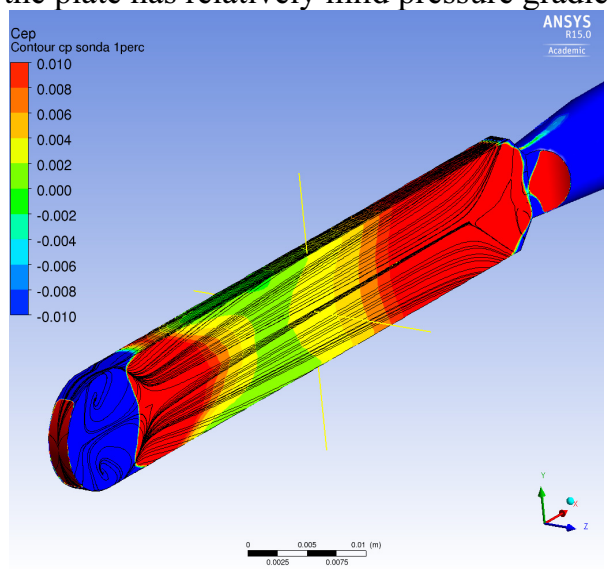

Figure 9. Pressure coefficient at zero yaw

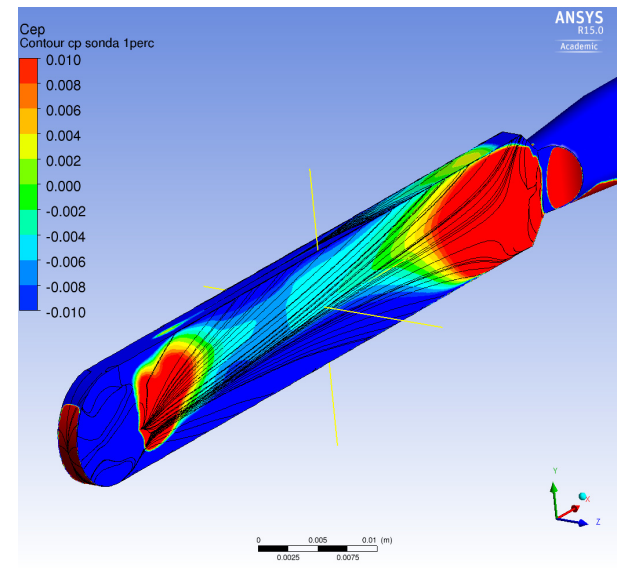

Figure 10. Pressure coefficient at angle of attack $\alpha=10^{\circ}$

An important feature of the probe is wider beam, which creates stagnated area with higher pressure in balance to lower pressure in front part. The figures 10 and 11 show very good insensitivity to lateral cross flow. Sensitivity to yaw angles in vertical plane (i.e. angle of attack) is higher, but better than sensitivity of static tubes.

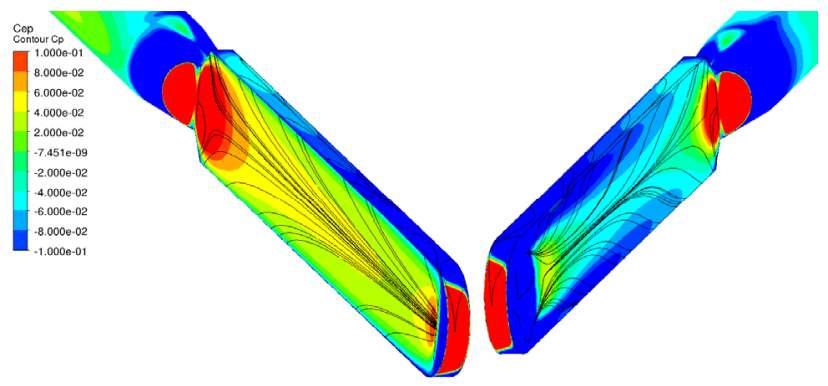

Figure 11. Pressure coefficient at yaw angle $\beta=10^{\circ}$

The static error comparison of the CFD analysis results and Prandtl's static probe is on the figure 12. It is apparent, that the Broezel flat static probe has a much wider range of yaw angles, where the static error is below $1 \%$ (more than $10^{\circ}$ ).

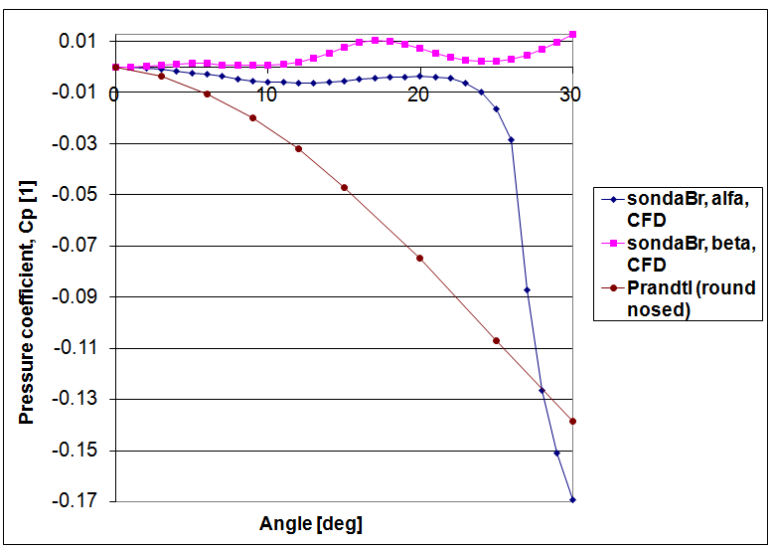

Figure 12. Comparison of the influence of yaw on static error of Broezel and Prandtl static probes

\section{Experimental measurement of Broezel flat static probe in wind tunnel}

For confirmation of insensitivity of the Broezel flat static probe the experimental measurement in wind tunnel was performed. First step was the manufacture of the probe using 3D printer. The material was PLA (polylactide) polymer and a surface of the probe was grinded in order to achieve its hydrodynamic smoothness.

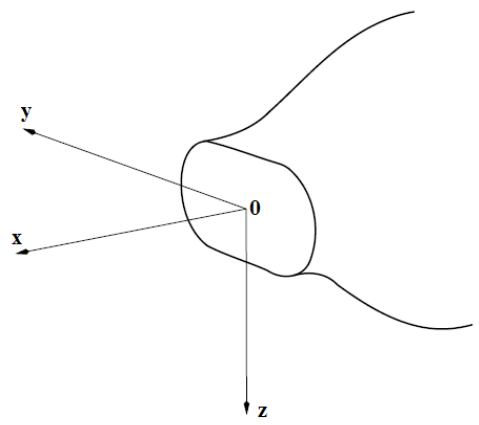

Figure 13. Coordinate system of the measurement section

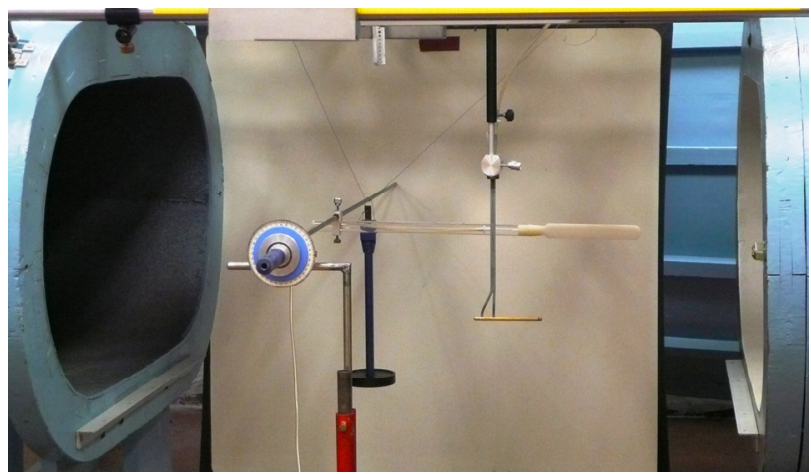

Figure 14. Position of the Broezel probe in a measurement section of the wind tunnel 
The Broezel flat static probe was placed in a test section of the subsonic wind tunnel. The probe is positioned in the centerline of measurement section, with its static ports located on $\mathrm{x}$-axis, $0.3 \mathrm{~m}$ from the origin by the figure 13. For resulting configuration of the measuring equipment in the measurement section see the figure 14 .

The velocity of the airflow was approximately $25 \mathrm{~m} / \mathrm{s}$ $\left(90 \mathrm{~km} \mathrm{~h}^{-1}\right)$. The position of the probe relatively to the wind tunnel was in the same position during all measurements. The angle of attack and yaw angle of the probe was varied in the range $\pm 30^{\circ}$, always varying only one parameter at the same time and holding the other parameter at the zero value. The results of the wind tunnel experiment are shown on the following graphs.

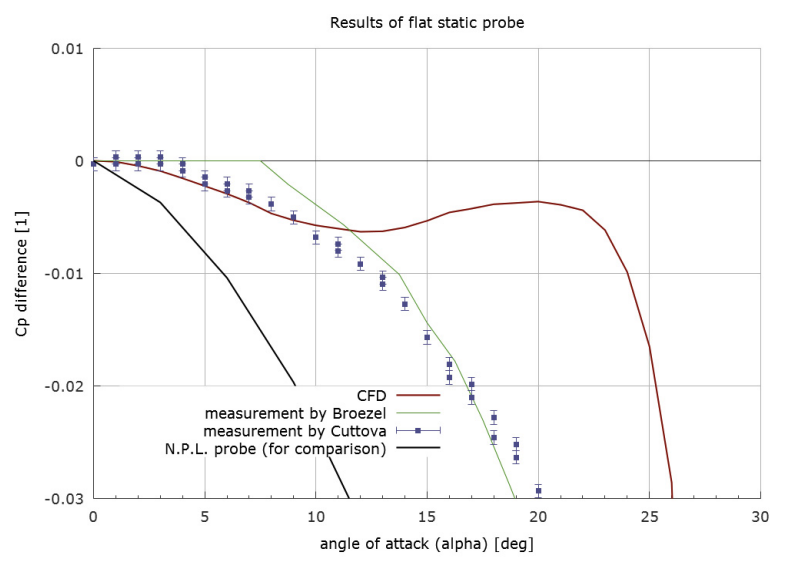

Figure 15. Angle of attack sensitivity of Broezel flat static probe

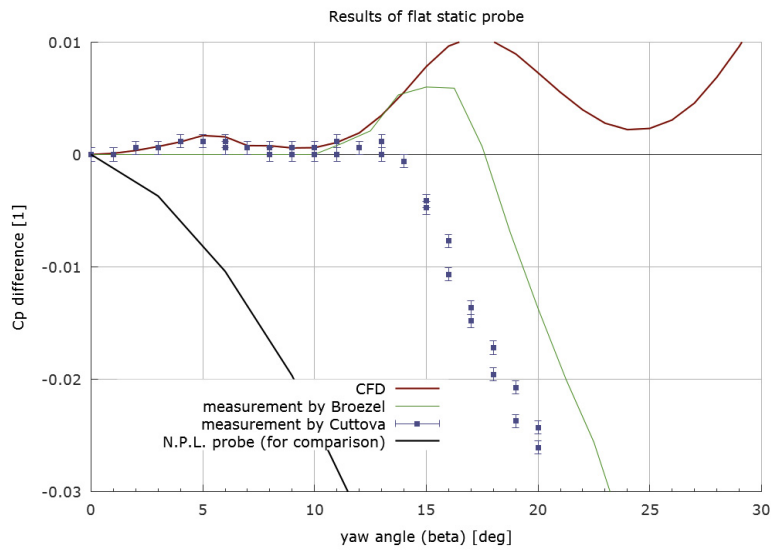

Figure 16. Yaw sensitivity of Broezel flat static probe

\section{Conclusions}

CFD results and experimental results in the range of angles up to $10^{\circ}$ are similar and they have the same trend. At high angles, the measurement in wind tunnel has the same trend as the measurement by Broezel. The differences may be the result of relatively high turbulence in the wind tunnel. There is also another unknown - the value of the Reynolds number in Broezel's experiment.
Both the CFD results and experiment results confirm good properties of the probe. The Broezel flat static probe is suitable for accurate measurement of the static pressure with the yaw in the range of $3^{\circ}$ with the static pressure error $0.1 \%$. For comparison, Prandtl's probe must be set in the direction of the airflow 4 times more accurately.

\section{References}

1. J. B. Barlow, W. H. Rae, A. Pope, Low-speed wind tunnel testing (1999)

2. R. L. Beach, et al., US Patent 2876640 (1956)

3. J. P. Holman, Experimental Methods for Engineers (2011)

4. L. N. Krause, C. C. Gettelman, ISA Proc., 7, 134137 (1952)

5. R. W. Miksad, Appl. Meteor., 15, 1215-1225 (1976)

6. E. Ower, R. C. Pankhurst, The measurement of air flow (1966)

7. R. C. Pankhurst, D. W. Holder, Wind-tunnel technique (1952)

8. A. M. O. Smith, A. B. Bauer, J. of Fluid Mech., 44, 513-528 (1970)

\section{Acknowledgement}

This work has been supported by the grant KEGA 028TUKE-4/2013 (An integrated program of study "Unmanned Aircraft Systems"). 